\title{
Adaptive Changes in the Psyche of Homo Sapiens during the Period of the Singularity (Part 2)
}

\author{
Alexander G. Kruglov, PhD, ScD*; Andrey A. Kruglov, PhD \\ Central Research Institute of Radiation Diagnostics \\ Moscow, the Russian Federation
}

\begin{abstract}
Creativity, the integrative function of the psyche of Homo sapiens (HS), which arose about 50,000 years ago, allowed HS to project the image of the goal (IG), transformed into a "symbol," into the external environment. The projection constructs of the psyche have become autonomous fragments of the environment in the HS perception, not being its derivatives. Objective reality, perceived by HS, has acquired non-inherent properties: a mental product of the psyche that integrates the virtual and real components of the environment. The role of HS has evolved over the last 10,000 years, since the beginning of the agrarian revolution: from (1) a dependent subject controlled by external forces in an animated world to (2) "the crown of God's creation" in "theism" and, (3) to the status "Higher power" during the period, in which "God is Dead." Initially, HS exists in an incompletely real environment, with an increasing component of virtuality. With symbolic virtual content, HS supplemented or duplicated the entire surrounding world, creating a two-component habitat (virtual and real). The emergence and development of conceptual thinking (ConceptT) led to a partial "devirtualization" of the environment, the removal of restrictions on scientific knowledge, the rapid growth of technology and social dynamics. The result of technological development was, in the recent past, a temporary resolution of the primary frustration: the establishment of the current equilibrium in the relationships with the regulatory "dissociated symbol"- the virtual "information universe" (IU). The IU, defining as the interference of "media" with the "information body" of the Internet, we consider as a unified information space, integrated with reality and in total constituting the HS habitat. Clip thinking (ClipT), qualitatively different from Concept $\mathrm{T}$, is a new operating system of the psyche, a moderator of adaptation to a new, virtualized environment. A technological derivative of mental activity HS - the IU-without the participation of conscious forms of mental activity, transforms the algorithms of thinking, i.e. formats the psyche as a whole with adaptation to qualitative and quantitative changes in the virtual component of the environment, and to the perspectives on the development of technologies during the singularity.(International Journal of Biomedicine. 2021;11(1):68-72.)
\end{abstract}

Key Words: clip thinking $\bullet$ conceptual thinking $\bullet$ singularity $\bullet$ virtualization $\bullet$ symbol $\bullet$ Internet $\bullet$ media $\bullet$ information revolution

For citation: Kruglov AG, Kruglov AA. Adaptive Changes in the Psyche of Homo sapiens during the Period of the Singularity (Part 2). International Journal of Biomedicine. 2021;11(1):68-72. doi:10.21103/Article11(1)_PV

\section{Abbreviations}

CC, creative construct; HS, Homo sapiens; IG, the image of the goal; ClipT, clip thinking; ConceptT, conceptual thinking; DMN, the default mode network; IU, information universe.

Creativity, as a specific species feature of the psyche of Homo sapiens (HS), as the ability to produce the predictive hypotheses that cannot be derived directly

*Corresponding author: Alexander G. Kruglov, PhD, ScD. Central Research Institute of Radiation Diagnostics. Moscow, the Russian Federation.E-mail: krag48@mail.ru from the initial conditions, appeared in HS as a result of a genetic mutation, or other (exogenous or interfering) causes, about 50,000 years ago. ${ }^{(1)} \mathrm{HS}$ (Cro-Magnons), having a new feature of the species ("creativity"), compared with Homo neanderthalensis, acquired a much greater range of adaptive behaviors, as well as a strategic advantage in conditions of interspecific competition, which resulted in dominating and 
then crowding out the competitive subspecies. ${ }^{(2,3)}$ Creativity created a unique for biological species ability to form flexible forms of adaptive behavior, change behavioral tactics, create technical means of hunting and war, as well as pictorial (artistic in our understanding) plots of achieving a future result (caves of Altamira, Montespan, Chauvet, etc. ${ }^{(4,5)}$, which do not require reactive behavior. That is, in the absence of the subject of the image, virtual images with real prototypes were created. CroMagnons also created complex three-dimensional models: a bear in the Montespan Cave. Such models could be used both for ritual purposes (future totem) and for practicing hunting skills. ${ }^{(5)}$ The operating systems of the Cro-Magnon psyche (thinking, memory, imagination, etc.), integrated creativity, made it possible to create the abstract image of the goal (IG). In the inevitable process of additions and interpretations, the IG, which received projection model characteristics, was transformed into a "symbol" (image + sense). ${ }^{(6)}$ Thus, the projection of the IG into the external environment, the virtualized or mock-up "symbol," in the perception of CroMagnons becomes an autonomous fragment of the habitat, not being its natural derivative. . $^{(2,7,8)}$

The system of primary abstract representations, transforming in generations, inevitably (already at the stage of lack of means of fixation) interferes, increasing in volume and becoming more complex in structure, increasing the degree of uncertainty. Only the person with uncertainty tolerance (priest, ideologue - divergent) is capable of systematizing an array of mythologemes, ${ }^{(2,7)}$ becoming an intermediary between the population and the complex structure of ideas, beliefs, mythologemes, myths. Integration of creative constructs (CC) by priests throughout generations creates stable virtual constructions that generally reflect reality in the form of sensually-specific associations perceived as real objects of the external environment. . $^{(2,7,8)}$

In other words, objective reality is endowed with not inherent properties, namely a mental product that integrates fragments of objective and virtual reality. Thus, a unified information space is created with the fixation of the individual's trajectory options in this system. A possibility of prognostic assessments forms, the level of anxiety decreases, the stability of society increases, and social negentropy is produced. With the accumulation of experience in the discrepancy between the forecasts and the results, the perception of their inconsistency grows. The result is the projection of control functions onto an external object with a potential that exceeds the capabilities of a person, the delegation of regulation and control functions to the object of worship. Direct and feedback links with an external control object (an object of worship) are always channeled, mediated by the "priest." (2,3,8)

For the first time in hominid history, a new need - the relationships with a symbolic image perceived as an objective reality - created an insoluble frustration as achieving equilibrium ("current equilibrium") in the relationships with the governing virtual creative construct-the "symbol." The manager CC ("symbol") has the location of the expected result outside the achievable and creates a primary insoluble frustration, which has an inexhaustible negentropic potential for creating homomorphic socio-psychological constructions of approaching the ideal, symbolic image of the goal (IG)..$^{(2,3)}$

A figurative, symbolic display of reality in cases, in which reality does not fit into the framework of a formal-logical and abstract display, forms mythologemes. Mythologeme is a stable psychological construct that reflects reality in the form of sensually-specific associations that are perceived as really existing. ${ }^{(9,10)}$ Mythologeme is able to direct the activity of an individual to achieve significant goals, ${ }^{(11)}$ creating a sequence of elements of ideas about reality and being a conceptual basis for behavior, which allows for some forms of behavior to equalize mythologeme and "motive."(7) The most important disposition of the motive is the "need,"(12) which forms the image of the future result - IG, which is the leading link in conscious behavior. The formation of IG is a psychophysiological stimulus for purposeful behavior and a starting point for the formation of an assessment scale for the speed of achieving a result, i.e. subjective time. In other words, in the psychological (subjective) time, the expected result (IG) has the fixed coordinate characteristics (virtual): a "reference point" in the future, while the present is always a temporary interval. ${ }^{(9)}$ That is, the virtual "future" (IG) determines the vector of the dynamics of the "present."

The emergence of writing, as a sign of the end of the prehistoric era (the Neolithic period), is a historical moment that determined the entire subsequent trajectory of the HS development, the beginning of the "agrarian revolution," the emergence of civilization, and the first network of horizontal structures (scribes, merchants, etc.). The dynamics of the rapid growth of technology is subordinated to the goals of the producing economy, extensive population growth (including wars as a tool), and irreversible processes of terraforming (starting with the destructive for the environment slashand-burn agriculture). The agrarian revolution transformed animistic beliefs into theistic religions, and the scientific revolution of the 18th and 19th centuries brought "theism" to the final formula: "God is Dead." ${ }^{(13)}$ In other words, the role of HS has evolved over the last 10,000 years, since the beginning of the agrarian revolution: from (1) a dependent subject controlled by external forces in an animated world to (2) "the crown of God's creation" in "theism" and, (3) to the status "Higher power" during the period, in which "God is Dead."

Throughout the history of HS, the CC (Symbol) extrapolated to the external environment has repeatedly transformed from the association of "image and meaning" to dissociation. The main forms of dissociation of the symbol: 1) the preservation of the "image" and "sense" when verbalization is taboo (some totems, the naming of "divine" emperors of China, etc.); 2) the elimination of the "image" while preserving the "sense" and verbalization (Islam, iconoclasm in Christianity, etc.); 3) the elimination of the "image" and verbalization, while maintaining the "sense" (Judaism, some forms of early Christianity), i.e. ultimate virtualization of the "symbol". In other words, HS, for most of its development, existed in an environment with an ever-increasing and increasingly complex virtuality component. We believe that it was the filling of the habitat with projection constructs of the psyche that transformed HS thinking in the following sequence: 1) concrete-objective, based on interaction with 
real objects; 2) visual-figurative, with the establishment of interconnections between objects and the possibility of a close forecast; 3) abstract-logical, operating with categories that are absent in reality. An example is the oldest written epics of the first city-kingdoms, Sumerian sources: "The Epic of Gilgamesh" and others. Virtual structures filled the entire habitat. Suffice it to recall the myths of Ancient Greece, which virtualized, filled the entire world with symbolic content. In this regard, the painting of the Middle Ages is indicative: a lack of perspective, a lack of time sequence, hierarchization of the world of "symbols," in which "a symbol is not a sign of reality, but replaces it, assuming the properties of reality."(14)

Egocentrism of pre-conceptual thinking, irreversibility of mental operations, insensitivity to logical contradictions, a transductive connection of pre-conceptual structures have created a habitat supplemented and expanded by virtual constructions. In other words, creativity, symbolic thinking, the intellectual activity of HS created a new, virtualized environment at the beginning of humanity's journey, in which the projection constructs of the psyche acquired the properties of real objects of equal size to natural objects. That is, HS initially lives in an incompletely real environment, with an increasing component of virtuality.

The global spread of typography, starting in the 15th century, and the emergence of "textual" culture initiated the emergence and development of conceptual thinking (ConceptT), which became the dominant type of thinking that shapes the psyche as a whole. We consider thinking as an integral function of the psyche, a special kind of mental and practical activity, including cognitive and transformative functions. It should be noted that Concept $T$ does not exist outside of verbal thinking, without words, in contrast to instincts and appetence. The sequential creation of a printed text ("general, whole") from separate "signs" is an individual, personified way of creating an "image" that has semantic content, i.e. "concept." The reading process is a way of step-by-step creation of an independent "image," a "synthesis" function. An intelligent operation with the opposite vector is "analysis" ("assemblydisassembly" of the image). Comparison of synthesized "images" makes it possible to highlight common features (abstraction), with the subsequent unification of different images into one category (generalization) and integration into one system, constituting a "concept." We have simplified the description of the algorithm of an independent, individual, based on printed text, construction of an integral "image" that has semantic content and unites disparate elements, i.e. "concept."

We believe that the rapid growth of the exponential schedule of technological development ${ }^{(15-17)}$ in the 18th-20th centuries is associated with a fairly high, above-threshold population level of the development of ConceptT based on textual education. Caused by the development and spread of ConceptT, the transformation of the psyche in significant population formations initiated radical changes in the structures of society, changing the categories of "possible" and "acceptable," creating new ethics.

In other words, ConceptT, which forms "independent images" based on the "sign" information of printed texts, over 300-350 years (from Gutenberg,1439), having reached quantitatively "critical population mass," initiated social dynamics and transformed the structure of society generally. The result of the changes in thinking that initiated the dynamics of society was a radical change in basic individual goals: from "service and devotion" to "independence and individualism." The spread of ConceptT in all social strata of the changed structure of society revealed the carriers of "Creativity", independent of class restrictions, who were given the opportunity to realize their potential in all types of human activity: from military spheres to scientific laboratories.

The ability to analyze, synthesize, construct, and structure the images and concepts, potentiated by the default mode network (DMN), led to the rapid development of scientific knowledge about the natural laws of the real environment, the exponential growth of scientific knowledge and technology, and a decrease in the volume and influence of the virtual component of the surrounding world.

The set of new knowledge and skills has radically rebuilt the structure of relationships with the former objects of worship of cults and confessions. An increase in the number of individuals who possessed an independent ConceptT, capable of analyzing and synthesizing, led to a bifurcation of the final target mythologemes: from theistic canons to an abstract "Supreme Being", heterogeneous "Just Societies" and so on, which shared the formula "God is Died" (Friedrich Nietzsche, 1882), the absence of a personified object of worship, and new (humanistic) ideals-symbols. These new CCs were united by humanistic IGs, which removed the limitations of scientific knowledge but are still beyond the attainable. We believe that this was the main motive (the same frustration, which has a new humanistic content) that initiated the wave of population and social dynamics of the 18-20 centuries. The result was a change in the role of HS in own perception and a transformation into a "Supreme Being" took place, accompanied for some time by a feeling of boundless power that did not have the limitations of the ethical nature of the era of theism. This period (the late nineteenth and early twentieth century) was accompanied by rapid scientific development, turbulent events in social dynamics, disastrous advances in war, and terraforming technologies. With no solutions for "primary frustration" for 50,000 years, the need of HS in equilibrium in the parametric relationships with an external control object that was beyond the reach of the attainable, received a temporary solution in the late 20th and early 21 st centuries. This phenomenon made it possible for dialogue, direct contact (through the operating systems of the Internet and social media) with an external object of technological genesis, which has the properties of regulation and control, a universal virtual product of human activity the "information universe" (IU). Generalized characteristics (the absence of the "image" with the preservation of "sense" and verbalization) allow constructively categorizing IU as a "dissociated symbol." The expanding range of regulatory functions of the technological product of the HS activity (IU) and the possibilities of satisfying the physical and mental needs of a person tends in the future to replace them with a virtual product. 
An obstacle to full contact with IU is ConceptT with analytic-synthetic (critical) functions, conservative stability, and the desire (created by the specifics of textual learning) to build autonomous images by operating systems of the psyche on the basis of cause-and-effect relationships. The reciprocal relationship of perception and processing of incoming information, the structuring action of DMN that completes the phase of perception, also prevents the processing of sequences that are not interrelated. The perception of environmental images that are not in causal relationships and are not interconnected sequences form "clip thinking" (ClipT). ${ }^{(18,19)} \mathrm{A}$ 6-fold excess of the speed of ClipT compared to ConceptT is accompanied by a decrease in the activity of DMN and analytical and synthetic functions. ClipT forms the ability to perceive a larger (compared to ConceptT) amount of short volumes of information per unit of time, with an increase in the total number and range of heterogeneous units of incoming information, increasing the multitasking of thinking. ${ }^{(20)}$

Differences between ClipT and ConceptT form stable differences in the trajectories of the development of the psyche as a whole. In ClipT, the exhaustion of the role of the linear sequence of "signs" as the basis of cultural development, ${ }^{(21)}$ a decrease in the criticality of thinking, insensitivity to logical contradictions, the absence of semantic completeness, ${ }^{(22)}$ the destruction of the context and internal semantic connections, and the fragmentation of perceived images form a deficient view of the real environment. ClipT partially returns thinking to the pre-text era, archaizes the structure of the psyche as a whole. In perception, preference is given to multiple incoherent episodes, in contrast to completed story media models. . $^{(23,24)}$ In ClipT, one's perceptions are taken to be equivalent to the connections of objects of perception.

Media moderates perception, creating and imposing ready-made, formed operational images, initiating purposeful behavior significant groups of the population through a variety of communicative operators. Here are just a few examples: 1) Fashion in all its manifestations, with an endless succession of replaceable "images" (without content and interconnected sequences), creating massive unified forms of imitative behavior; 2) Information and analytical programs that create suggestive logical constructions on any given topic; and many other things that form unified forms of population-level behavior with the dynamics of globalization, increasing the potential of manipulative technologies. The rapidly increasing interference of media with the information body of the Internet has formed a virtual IU: a universal information space that interferes with "reality" and, in total, makes up the HS habitat. We believe that the quantitative ratios of "reality" and the complementary IU with the constantly accelerating growth of IU are variable quantities.

ClipT, including archaic "thinking in complexes" and "paralogical thinking," accompanied by a decrease in analytical and synthetic functions, is a derivative of the IU, which is characterized by a rapid increase in the speed, density, and chaos of the information flow. It is ClipT, developing and improving, adapts the psyche as a whole to a new, more and more virtualized environment. The new integral environment is gradually leveling the ethical and moral limitations of the "theistic era," creating (first in the virtual component: computer games, communication in social networks, etc.) forms of behavior that reduce the role of moral and other psychological regulatory mechanisms. The next stage is the extrapolation of the solutions and behavior tactics familiar for the virtual environment to the environment as a whole, without taking into account the boundaries between the virtual and real components.

In other words, the present state and prospects for the development of HS have reliable signs of an adaptive transformation of the psyche as a whole towards the "pre-conceptual" level, archaization, accompanied by a decrease in restraining ethical regulators and the creation of an environment with an increasing virtual component of technological genesis - the IU.

Changing the boundaries of "acceptable" and "possible," infinitely expanding the user's virtual potential through a variety of operational modes of moderation, the IU has formed a multicomponent habitat that transforms the HS psyche. That is, the technological derivative of intellectual activity HS (the IU) determines the trajectory of the transformation of the psyche HS without the participation of conscious forms of mental activity, forming the type of thinking that is optimal for the changed structure of the living environment. The practically uncontrolled growth of technology in all areas of knowledge accelerates the adaptive transformation of the psyche, the changes of which cannot be limited to thinking.

Currently, in our opinion, we are in a transitional period of transformation of the HS psyche into a new quality, with the emergence of new operating systems, one of which, observed in development, is defined as ClipT. Without the goal of making forecasts for the development of HS, we believe that the interference of the main directions of genetic engineering, cyborgization, chipping and development (up to implantation) of interfaces with computer technology, with the subsequent qualitative transformation of the physical and mental properties of HS and a change in the role of perceived forms of mental activity, is highly probable in the near future. We believe that in the future, new physical, psychophysiological, mental properties of HS are more compatible with high-speed, easily switchable ClipT in contrast to ConceptT, which has insufficient speed characteristics, forms stable (conservative) mental constructs, and develops the ability to devirtualize the objective world.

Thus, technologies - a product of HS intellectual activity - from a certain already passed level of development, without the conscious participation of the subject, format the HS psyche, adapting it to new qualitative and quantitative levels of virtualization of the environment, the prospects for the development of the technologies themselves during the singularity. ClipT is only one registered and measurable integral indicator of the dynamics of changes in the psyche.

\section{Conclusion}

Creativity, the integrative function of the HS psyche, which arose about 50,000 years ago, allowed HS to project IGs, transformed into a "symbol," into the external 
environment. The projection constructs of the psyche have become autonomous fragments of the environment in the HS perception, not being its derivatives. Objective reality, perceived by HS, has acquired non-inherent properties: a mental product of the psyche that integrates the virtual and real components of the environment.

Initially, HS exists in an incompletely real environment, with an increasing component of virtuality. The emergence and development of ConceptT led to a partial "devirtualization" of the environment, the removal of restrictions on scientific knowledge, the rapid growth of technology and social dynamics. The result of technological development was, in the recent past, a temporary resolution of the primary frustration: the establishment of the current equilibrium in the relationships with the regulatory "dissociated symbol"- the virtual IU. The IU, defining as the interference of "media" with the "information body" of the Internet, we consider as a unified information space, integrated with reality and in total constituting the HS habitat. ClipT, qualitatively different from ConceptT, is a new operating system of the psyche, a moderator of adaptation to a new, virtualized environment. A technological derivative of mental activity HS- the IUwithout the participation of conscious forms of mental activity, transforms the algorithms of thinking, i.e. formats the psyche as a whole with adaptation to qualitative and quantitative changes in the virtual component of the environment, and to the perspectives on the development of technologies during the singularity.

\section{Competing Interests}

The authors declare that they have no competing interests.

\section{References}

1. Klein RG. The human career. Human biological and cultural origins. Chicago: The University of Chicago Press; 1989.

2. Kruglov AG. Creativity as a Determinant of the Development of Homo Sapiens. International Journal of Biomedicine. 2016;6(4):298-302.

3. Kruglov AG. Creativity as a Determinant of Intraspecific Aggressive Properties of the Psyche of Homo Sapiens.
International Journal of Biomedicine. 2017;7(2):150-154.

4. Devlet E. Altamira: at the origins of art. M.; 2004.

5. Bray W, Trump D. The penguin dictionary of archaeology. (Translated by Nikolaev GA). M.: Progress; 1990.

6. Losev AF. Essays on ancient symbolism and mythology. 1993. M.: Misl; 1993. [In Russian].

7. Kruglov AG. A Mythologem as a Determinant of GoalDirected Behavior. International Journal of Biomedicine. 2015;5(4):231-234.

8. Frazer JG. The Golden Bough: A Study in Magic and Religion. Translated from English into Russian. Moscow: TERRA-Knizhnii Klub; 2001.

9. Rubinshtein SL. Fundamentals of general psychology. St. Petersburg; 2003. [In Russian].

10. Jung CG. Archetype and Symbol. Translated from English into Russian. M.: Kanon; 1991.

11. Toporkov AL. Myth: tradition and psychology of perception. The myth and mythology in modern Russia. Moscow; 2000. [In Russian].

12. Shvyrkov VB. Introduction to objective psychology. Neuronal basics of psychics. Moscow: Psychology Institute of the Russian Academy of Sciences; 1995. [in Russian].

13. Mozheiko MA. History of Philosophy. Encyclopedia. Minsk. 2002:987-988. [In Russian].

14. Gurevich AJ. Categories of Medieval Culture. M.; 1984. [In Russian].

15. Panov AD. Singular point of history. Social sciences and modernity. M. MSU; 2005:122-137. [In Russian].

16. Snooks GB. Uncovering the laws in Global history. Social Evolution \& History. 2002;1(1):25-53.

17. Snooks GD. The dynamic society. Exploring the source of global change. London, NY, Routledge; 1996.

18. Girenok FI. Clip consciousness. M. Akademicheskii Prospect; 2014. [In Russian].

19. Girenok FI. Clip consciousness. M. Prospect; 2016. [In Russian].

20. Rosen L. Me, My Space and I: Parenting the Net Generation. NY; 2007.

21. McLuhan M. The Gutenberg Galaxy: The Making of Typographic Man. M. Academic project (Translation from English into Russian); 2005.

22. Golovin SJ. Dictionary of practical psychologist. M.: Harvest; 1998. [In Russian].

23. Toffler E. Shock of the future. M. AST; 2008. [In Russian]. 24. Toffler E. The Third Wave. M. AST; 2010. [In Russian]. 